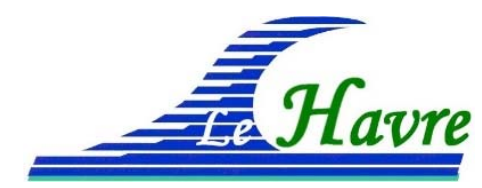

XVI èmes Journées Nationales Génie Côtier - Génie Civil

Le Havre, 2020

DOI:10.5150/jngcgc.2020.030 (C) Editions Paralia CFL

disponible en ligne - http://www.paralia.fr - available online

\title{
Eulerian-Eulerian two-phase flow Large Eddy Simulation of sheet flows under waves
}

\author{
Antoine MATHIEU ${ }^{1}$, Zhen CHENG ${ }^{2}$, Julien CHAUCHAT ${ }^{1}$, \\ Cyrille BONAMY ${ }^{1}$, Tian-Jian HSU $^{2}$
}

1. Laboratoire des Écoulements Géophysiques et Industriels, Grenoble INP, CNRS, Université Grenoble Alpes, 1209-1211 rue de la Piscine, 38400 Saint-Martin d'Hères, France.

antoine.mathieu@univ-grenoble-alpes.fr

2. Center for Applied Coastal Research, University of Delaware, 259 Academy street, Newark, DE 19716, USA.

\begin{abstract}
:
Beach morphological evolution is significantly affected by the very energetic flow conditions associated with storms. Conventional morphological models rely on bed shear stress based empirical formulas for sediment transport. Most of these formulas have been developed for uniform and steady flows and even though a significant progress has been made, some mechanisms are still not well reproduced by engineering sediment transport models such as the occurrence of plug flows or the phase-lag effect for fine sand. In this contribution, we observe that the turbulence resolving Eulerian-Eulerian two-phase flow model is able to reproduce the mechanisms responsible for the phase-lag effect, which is associated with sediment burst events that occur near flow reversal. In future work, this methodology will be used to deduce the relevant dimensionless numbers controlling this phenomenon. In the long term, this approach should allow to develop more physicallybased parameterizations for wave-driven sediment transport formulas for large-scale applications.
\end{abstract}

\section{Keywords:}

Two-phase flow simulations, Large Eddy Simulation, Sediment transport, waves, Phaselag effect. 


\section{Thème 2 - Dynamique sédimentaire}

\section{Introduction}

Understanding the different mechanisms responsible for initiation of motion, suspension, transport and deposition of sediments is essential to predict morphological evolution of the nearshore (LESSER et al., 2004). Our ability to predict sediment fluxes depends on our physical understanding of the underlying physical processes.

During storms, the undertow current generated by wave breaking and set-up induces a net offshore directed sediment flux responsible for the offshore migration of sand bars (GALLAGHER et al., 1998). During low energy periods after storms, sand bars migrate onshore (GALLAGHER et al., 1998) under the effect of waves skewness and asymmetry (ELGAR et al., 2001). Until recently, beach morphodynamical models were unable to reproduce the onshore sand-bar migration (VAN RIJN et al., 2011). Sediment transport experiments in U-tubes or water tunnels i.e. without free surface have been performed in order to characterize the effect of wave skewness on sediment fluxes (DOHMENJANSSEN et al., 2002; O'DONOGHUE \& WRIGHT, 2004a \& 2004b). This experimental data has been used to develop new sediment transport formulas under waves as a function of their skewness and asymmetry. With these new formulas, it is possible to reasonably predict the onshore and offshore sediment fluxes depending on the wave conditions. However, as the wave skewness generally induces a net onshore directed sediment flux for medium sand ( $\left.\mathrm{d}_{50} \sim 200 \mu \mathrm{m}\right)$, DOHMEN-JANSSEN et al. (2002) have shown that for fine sand $\left(\mathrm{d}_{50} \sim 150 \mu \mathrm{m}\right)$, the net sediment flux was offshore oriented. In that case, there is a phase-lag between the sediment flux and the local bed shear stress during the wave cycle, which is often called phase-lag effect. Particles are set in suspension during the wave crest and remain suspended during flow reversal. Consequently, they are transported offshore during the wave trough, generating a net offshore sediment flux (DOHMEN-JANSSEN et al., 2002). This phenomenon can be explained by the relatively small settling velocity for fine sand.

More recently, VAN DER A et al. (2013) proposed a practical formula to predict sand transport under the action of current and non-breaking waves based on a database containing more than 226 experiments. This formula is able to predict the sediment flux with less than a factor two in approximately $80 \%$ of the analyzed configurations. Even if significant progress has been made on beach morphological prediction, there is no clear understanding of the fine scale processes responsible for the phase-lag effect.

\section{Eulerian-Eulerian two-phase flow model}

In order to investigate fine-scale turbulent and granular processes under waves, a turbulence resolving Eulerian-Eulerian two-phase flow model for Large Eddy Simulation (LES) is used. In this framework, the carrier and disperse phases are both seen as continua. Filtered continuity and momentum equations for the fluid (Eq. (1) and (3)) and solid (Eq. (2) and (4)) phases are defined following: 


$$
\begin{aligned}
& \frac{\partial(1-\bar{\phi})}{\partial t}+\frac{\partial(1-\bar{\phi}) u_{l}^{f}}{\partial x_{i}}=0 \\
& \frac{\partial \bar{\phi}}{\partial t}+\frac{\partial \bar{\phi} \widetilde{u}_{L}^{s}}{\partial x_{i}}=0 \\
& \frac{\partial(1-\bar{\phi}) \rho f \widetilde{u}_{l}^{f}}{\partial t}+\frac{\partial(1-\bar{\phi}) \rho f \tilde{u}_{\imath}^{f} \tilde{u}_{\jmath}^{f}}{\partial x_{j}}=-(1-\bar{\phi}) \frac{\partial \bar{f} f}{\partial x_{i}}+\frac{\partial}{\partial x_{j}}\left(\widetilde{T}_{l \jmath}^{f}+\sigma_{i j}^{f, s g s}\right)+\frac{\bar{\phi} \rho^{s}}{t^{s}}\left(\widetilde{u}_{\imath}^{f}-u_{l}^{S}\right) \\
& +\rho^{f}(1-\phi) g_{i}
\end{aligned}
$$

$\frac{\partial \bar{\phi} \rho^{s} \hat{u}_{l}^{s}}{\partial t}+\frac{\partial \bar{\phi} \rho^{s} \widetilde{u}_{l}^{s} \widetilde{u}_{j}^{s}}{\partial x_{j}}=-\bar{\phi} \frac{\partial \bar{P} f}{\partial x_{i}}-\frac{\partial \bar{P}^{s}}{\partial x_{i}}+\frac{\partial}{\partial x_{j}}\left(T_{l j}^{s}+\sigma_{i j}^{s, s g s}\right)-\frac{\bar{\phi} \rho^{s}}{t^{s}}\left(\widetilde{u}_{l}^{f}-\tilde{u}_{l}^{s}\right)+\rho^{s} \phi g_{i}$

with $\bar{\phi}$ the filtered sediment volumetric concentration, $\tilde{u}_{\imath}^{f}=\overline{(1-\phi) u_{i}^{f}} /(1-\bar{\phi})$ and $u_{i}^{s}=\overline{\phi u_{i}^{s}} / \bar{\phi}$ the Favre filtered fluid and solid phases velocities respectively, $\rho^{f}$ and $\rho^{s}$ the fluid and solid densities, $\bar{P} f$ and $\widehat{T}_{l \jmath}^{f}$ the filtered fluid pressure and shear stress tensor, $\overline{P^{s}}$ and $\mathcal{T}_{l j}^{s}$ the solid phase pressure and shear stress tensors modeled using the kinetic theory of granular flows, $t^{s}$ the particle response time modeled following the nonlinear drag law from GIDASPOW (1986) and SCHILLER \& NAUMANN (1933) and $\sigma^{f, s g s}$ and $\sigma^{s, s g s}$ the fluid and solid sub-grid scale stress tensor modeled using a dynamic procedure.

The two-phase flow model called sedFoam is implemented in the open-source computational fluid dynamics toolbox OpenFoam (JASAK \& UROIC, 2020) and solves the Eulerian-Eulerian two-phase flow mass and momentum equations using a finite volume method and a Pressure-Implicit with Splitting of Operators (PISO) algorithm for velocity-pressure coupling. The model has been successfully applied and validated against configuration of unidirectional sheet flow (CHENG et al., 2018). More information about consistency, algorithm and numerical implementation can be found in CHAUCHAT et al. (2017).

\section{Two-phase flow simulations}

Two experimental configurations from O'DONOGHUE \& WRIGHT (2004a, 2004b) are reproduced using the two-phase flow model sedFoam. Both configurations, are idealized flow conditions of the nearshore environment performed in a U-tube designed to observe oscillatory sheet-flow. The flow conditions are the same for both configurations with symmetric sinusoidal waves having maximum orbital velocity $U=1.5 \mathrm{~m} / \mathrm{s}$ and period $\mathrm{T}=5 \mathrm{~s}$. For the first configuration, medium sand with $\mathrm{d}_{50}=280 \mu \mathrm{m}$ is used whereas in the second configuration they used fine sand with $\mathrm{d}_{50}=150 \mu \mathrm{m}$. The numerical domain is a rectangular shaped-box with periodic boundary conditions in the streamwise and spanwise directions and a symmetric boundary condition applied at the top.

Vertical concentration profiles at different moments of the wave period are presented in figures 1 and 2 for medium and fine sand configurations respectively. The two-phase flow 


\section{Thème 2 - Dynamique sédimentaire}

model predicts sediment concentration profiles in good agreement with experimental observations for medium sand. For the configuration using fine sand, the erosion during flow peak is overestimated compared with the experiments. Even if sedFoam does not provide quantitative results with fine sand, a qualitative agreement can be observed. Indeed, at flow reversal, the particles do not settle to the bed, a plateau can be observed at a volume fraction $\phi \approx 0.2$ in the experiments whereas the same plateau is observed at $\phi \approx 0.4$ in the simulations.

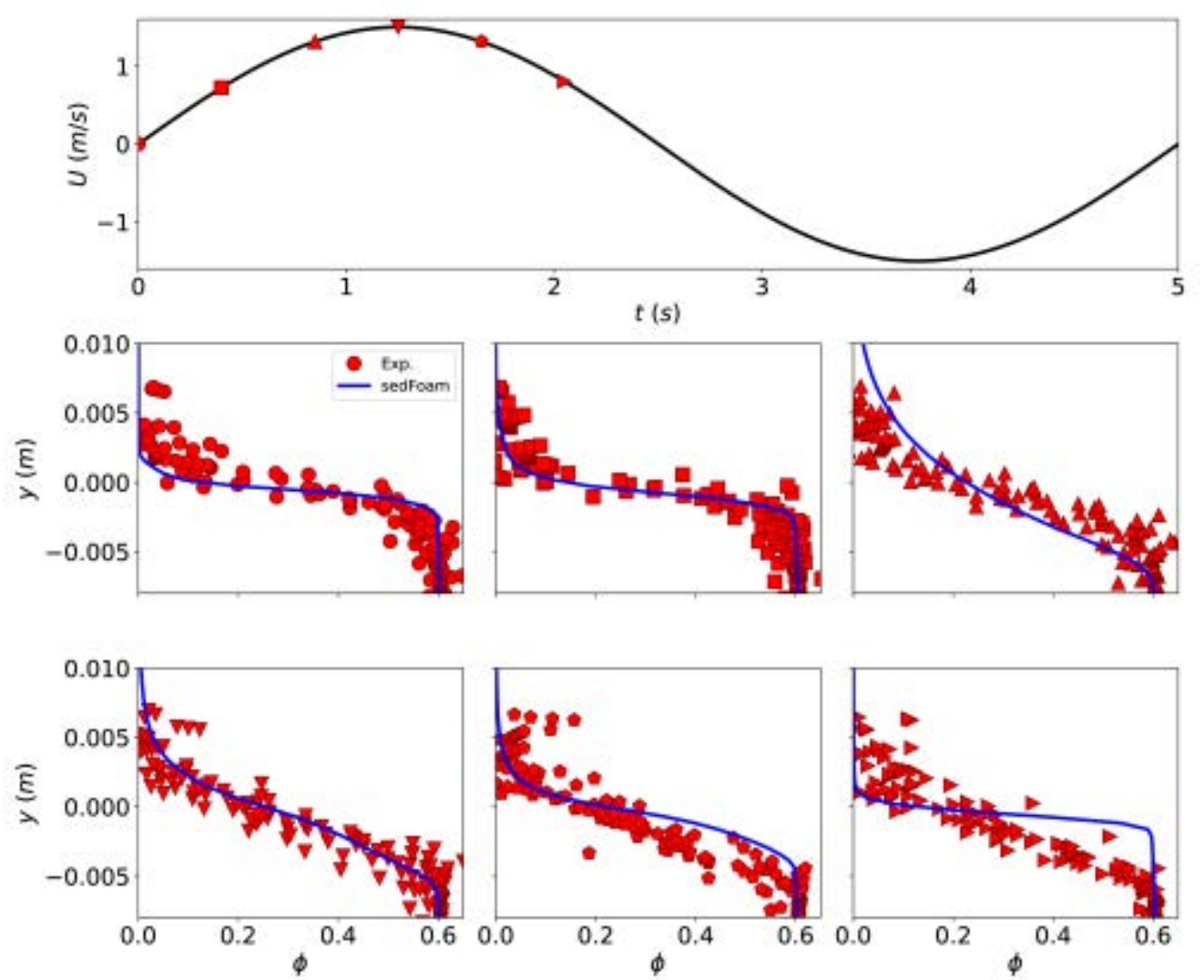

Figure 1. Concentration profiles obtained with sedFoam compared with experimental results for the medium sand configuration.

The fine sand is maintained in suspension during flow reversal via shear instability wellknown in transitional flows.

The phenomenon observed is responsible for the phase-lag effect. For skewed and/or asymmetric waves, fine sand remaining in suspension during flow reversal will be transported offshore during the wave trough potentially generating a net offshore sediment flux (DOHMEN-JANSSEN et al., 2002). 


\section{XVİ̀mes Journées Nationales Génie Côtier - Génie Civil \\ Le Havre 2020}
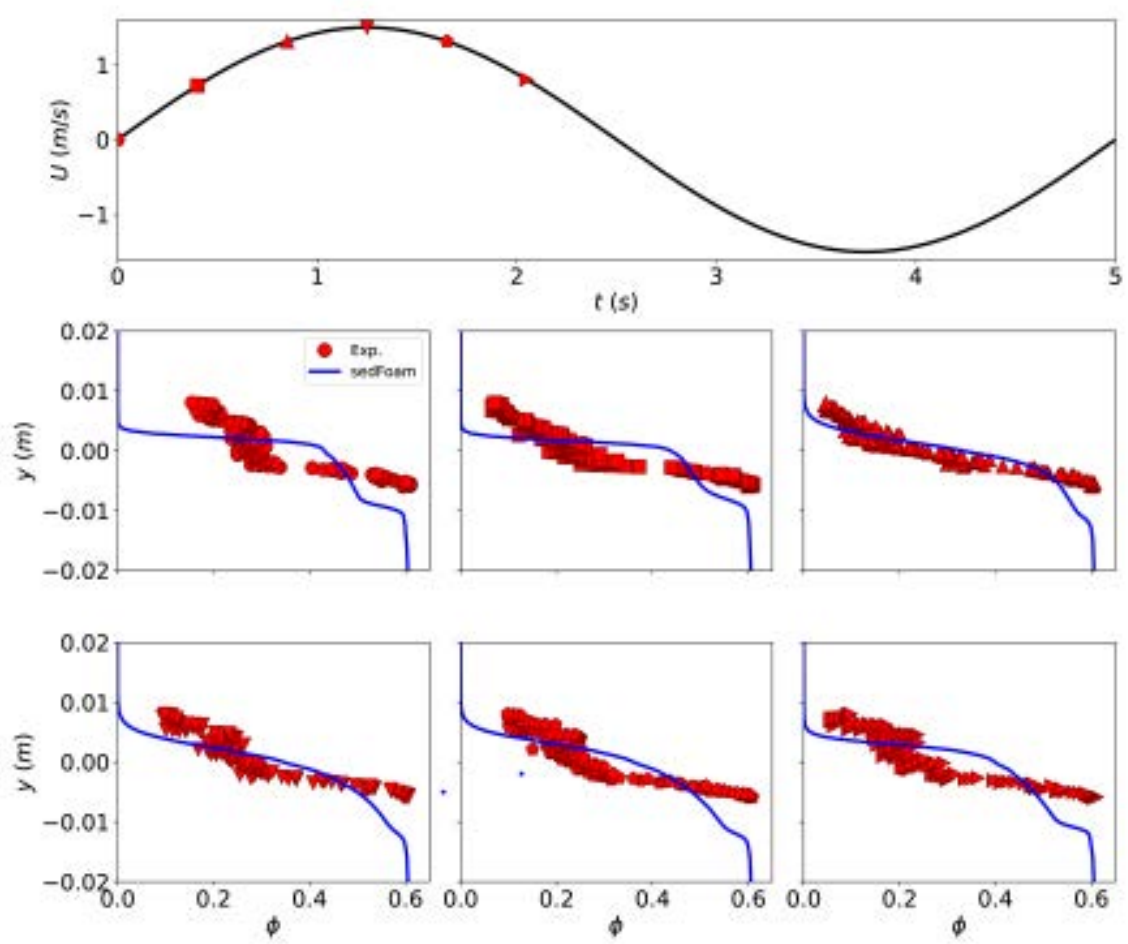

Figure 2. Concentration profiles obtained with sedFoam compared with experimental results for the fine sand configuration.

\section{Conclusion}

The turbulence resolving Eulerian-Eulerian two-phase flow model is able to reproduce the mechanism at the origin of the phase-lag effect and can therefore be a relevant tool to further investigate this phenomenon. Quantitative results are obtained for configurations using medium sand but only qualitative results are obtained for fine sand leaving room for improvement of the two-phase flow model. In a near future, this methodology will be used to explore the parameter space in terms of particle diameter and flow conditions in order to deduce the relevant dimensionless numbers controlling the phase-lag effect. This is the starting point toward incorporating this effect in sediment transport formulas for large-scale applications.

\section{References}

CHAUCHAT J., CHENG Z., NAGEL T., BONAMY C. HSU T.-J. (2017). Sedfoam-2.0: a 3-d two-phase flow numerical model for sediment transport. Geoscientific Model Development, Vol. 10 (12), pp 4367-4392. https://doi.org/10.5194/gmd-10-4367-2017

CHENG Z., HSU T.-J., CHAUCHAT J. (2018). An eulerian two-phase model for steady sheet flow using large-eddy simulation methodology. Advances in Water Resources, Vol. 111, pp 205-223. https://doi.org/10.1016/j.advwatres.2017.11.016 


\section{Thème 2 - Dynamique sédimentaire}

DOHMEN-JANSSEN C.M., KROEKENSTOEL D.F., HASSAN W.N., RIBBERINK J. S. (2002). Phase lags in oscillatory sheet flow: experiments and bed load modelling, Coastal Eng., Vol. 46(1), pp 61-87. https://doi.org/10.1016/S0378-3839(02)00056-X

ELGAR S., GALLAGHER E.L., GUZA R.T. (2001). Nearshore sandbar migration, J, Geophy. Res., Vol. 106(C6), pp 11,623-11,627. https://doi.org/10.1029/2000JC000389

GALLAGHER E.L., ELGER S., GUZA R.T. (1998). Observations of sandbar evolution on a natural beach. J. Geophys. Res., Vol. 103, pp 3203-3215. https://doi.org/10.1029/97JC02765 GIDASPOW D. (1986). Hydrodynamics of fluidization and heat transfer: supercomputer modeling. Applied Mechanics Reviews, Vol. 39 (1), pp 1-23. https://doi.org/10.1115/1.3143702 JASAK H., UROIC T. (2020). Practical Computational Fluid Dynamics with the Finite Volume Method, Cham: Springer International Publishing, pp 103-161. https://doi.org/10.1007/978-3-030-37518-8_4

LESSER G., ROELVINK J., VAN KESTER J., STELLING G. (2004). Development and validation of a three-dimensional morphological model. Coastal Engineering, Vol. 51(8-9), pp 883-915. https://doi.org/10.1016/j.coastaleng.2004.07.014

O'DONOGHUE T., WRIGHT S. (2004a). Concentrations in oscillatory sheet flow for well sorted and graded sands, Coastal Engineering, Vol. 50, pp 117-138. https://doi.org/10.1016/j.coastaleng.2003.09.004

O'DONOGHUE T., WRIGHT S. (2004b). Flow tunnel measurements of velocities and sand flux in oscillatory sheet flow for well-sorted and graded sands. Coast Eng., Vol. 51, pp 1163-1184. https://doi.org/10.1016/j.coastaleng.2004.08.001

SCHILLER L., NAUMANN A. Z. (1933) Über die grundlegenden Berechnungen bei der Schwerkraftaufbereitung. Ver. Deut. Ing., Vol. 77, pp 318-320.

VAN DER A D.A., RIBBERINK J.S., VAN DET WERF J.J., O'DONOGHUE T., BUIJSROGGE R.H., KRANENBURG W.M. (2013). Practical sand transport formula for non-breaking waves and currents. Coastal Engineering, Vol. 76, pp 26-42. https://doi.org/10.1016/j.coastaleng.2013.01.007

VAN RIJN L.C., TONNON P.K., WALSTRA D.J.R. (2011). Numerical modelling of erosion and accretion of plane sloping beaches at different scales. Coastal Eng., Vol. 58(7), pp 637-55. https://doi.org/10.1016/j.coastaleng.2011.01.009 